$\infty$

0

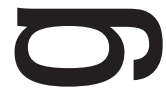

-

ת

1

$\longrightarrow$ 


\title{
SETE LAGOAS: A DINÂMICA FUNCIONAL DE UMA CIDADE MÉDIA E SUA INSERÇÃO NA REDE URBANA DE MINAS GERAIS
}

\author{
SETE LAGOAS: THE FUNCTIONAL DYNAMICS OF A MEDIUM CITY AND ITS \\ INSERTION IN THE URBAN NET OF MINAS GERAIS STATE
}

Marly Nogueira - UFMG

marlyn@click21.com.br

\begin{abstract}
Resumo
A cidade de Sete Lagoas é uma típica cidade média de Minas Gerais e, apesar de estar tão próxima da terceira maior região metropolitana do Brasil, desenvolveu uma respeitável autonomia em relação à metrópole belohorizontina. Partindo de indagações tais como àquelas que se referem aos objetivos, à gênese e à dinâmica dos processos socioespaciais que explicam a atual inserção de Sete Lagoas na rede urbana mineira, é que se desenvolveu esse trabalho. A posição geográfica de contato de duas grandes regiões fisionômicas e socioespaciais mineiras - as Gerais (o Sertão) e as Minas pode, certamente, constituir e explicar, numa primeira aproximação, a posição de relativa centralidade urbana conquistada por Sete Lagoas em sua região. Entretanto, outros fatores tais como os agentes sociais e suas estratégias e o modo como tais agentes se aproveitaram dessa posição geográfica para forjar aquela autonomia, são cruciais para tornar inteligível a socioespacialidade e a inserção de Sete lagoas na rede urbana mineira, na atualidade. 0 estudo desses processos constitui 0 escopo desse trabalho. Trata-se de uma tentativa de continuar trilhando uma tradição da Geografia Urbana brasileira - 0 estudo da cidade e sua hinterlândia -, tendo em vista o relativo abandono que a temática sofreu nos estudos urbanos brasileiros.
\end{abstract}

Palavras-chave: Sete Lagoas, Rede urbana, Minas Gerais, Socioespacialidade, centralidade urbana.

\begin{abstract}
The city of Sete Lagoas is a typical medium city of Minas Gerais State and, in spite of being so close to the third largest metropolitan area of Brazil, it developed a respectable autonomy in relation to the Belo Horizonte metropolis. From such inquiries as those that refer to the aims, the genesis and the dynamics of the sociospatial processes that explain the current insertion of Sete Lagoas in the Minas Gerais State urban net, it's that it grew this work. The geographical position of contact of two great physiognomic and sociospatial areas - the "Gerais" one (the hinterland) and the "Minas" can, certainly, to constitute and to explain, in a first approach, the position of relative urban centrality conquered by Sete Lagoas in its area. However, other such factors as the social agents and their strategies and the way as such agents took advantage of of that geographical position to forge that autonomy are crucial to turn intelligible the sociospatial and the insertion of Sete Lagoas in the Minas Gerais State urban net, at the present time. The study of those processes constitutes the mark of that work. It's treated of an attempt of continuing treading a tradition of the Brazilian Urban Geography - the study of the city and its hinterland -, tends in view the relative abandonment that such a theme suffered in the Brazilian urban studies.
\end{abstract}

keyword: Sete Lagoas, urban web, Minas Gerais state, sociospatiality, centrality. 
Sete Lagoas possui uma posição de destaque na região central de Minas Gerais. No que diz respeito aos aspectos populacionais, seu crescimento na última década demonstra tal assertiva. De acordo com o Censo do IBGE (2000), a população total alcançou os 184692 habitantes, suplantando outras cidades médias mineiras não metropolitanas, tais como, Divinópolis, Ouro Preto e Conselheiro Lafaiete, localizadas nessa mesma região central. Adicione-se a taxa de crescimento geométrico médio, cujo destaque é expressivo (Tabela 1).

Essa centralidade sete-lagoana, tornada visível ao longo da segunda metade do século XX, já havia sido observada por alguns estudos (BERNARDES, 1964, IBGE, 1972 e IBGE, 1987), nos quais a cidade figura com relativo destaque na hierarquia urbana nos sistemas estabelecidos. É confirmada posteriormente (IBGE, 1992, CETEC/IGA, 1997), quando novamente a cidade aparece com destaque nas regionalizações elaboradas, ou seja, ela é o centro de uma das mais de trezentas microrregiões geográficas identificadas em todo o país e, também, o centro de uma das vinte e cinco regiões administrativas nas quais fora dividido o Estado de Minas Gerais.

A região de influência direta de Sete Lagoas teve uma tendência de diminuir em direção sul, como decorrência do recrudescimento do processo de metropolização de Belo Horizonte. Entretanto, em direção noroeste, essa mesma região tem-se mantido estável durante um longo período e, embora possa ter perdido, em termos relativos, em atuação direta, não se pode afirmar que a influência sete-lagoana deixou de ser presente nessas direções. Ela ainda é significativa, porém de uma forma mais difusa e, dependendo da direção, possui diferentes graus de intensidade e de freqüência de relacionamentos, fato que faz de Sete Lagoas a principal cidade, a mais bem equipada de toda a região que fica entre os vales dos rios das Velhas e Paraopeba, desde os limites setentrionais da região metropolitana de Belo Horizonte até a represa de Três Marias. Na verdade, em direção oeste, o confronto de atuação regional sete-lagoana se dá com a área de atuação de Divinópolis que, assim como Sete Lagoas, parece ter mantido o respectivo comando de sua hinterlândia ao longo das últimas décadas.

A posição geográfica de Sete Lagoas, de contato entre duas grandes regiões fisionômicas e socioespaciais, ou seja, entre o Quadrilátero Ferrífero, zona de ocorrência predominante de minerais ferrosos e da floresta tropical úmida, como vegetação primitiva do centro-sul e leste de Minas Gerais (a região das MINAS) e a região dos calcários do Bambuí, com uma típica vegetação de cerrados, nos quais sobressaem os campos limpos e os cocais, conjugados a uma marcante presença das pastagens (a região das GERAIS), 
Tabela 1: Região central de Minas Gerais - Municípios selecionados população total (1991 e 2000) e urbana (2000) (números absolutos e valores relativos -\%).

\begin{tabular}{|c|c|c|c|c|c|}
\hline Município & $\begin{array}{c}\text { População } \\
\text { total } \\
1991\end{array}$ & $\begin{array}{c}\text { População } \\
\text { total } \\
2000\end{array}$ & $\begin{array}{c}\text { Tax. de cr. } \\
\text { geom. médio } \\
\text { 1991/2000 } \\
\text { (\% a.a.) }\end{array}$ & $\begin{array}{c}\text { População } \\
\text { urbana } \\
\text { total }\end{array}$ & $\begin{array}{c}\text { Part. na } \\
\text { população } \\
\text { total (\%) }\end{array}$ \\
\hline Abaeté & 20687 & 22330 & 0.85 & 18995 & 85.06 \\
\hline Baldim & 8452 & 8135 & -0.42 & 4810 & 59.13 \\
\hline Belo Horizonte & 2017127 & 2232747 & 1.13 & 2232747 & 100.00 \\
\hline Betim & 171237 & 306538 & 6.68 & 298116 & 97.25 \\
\hline Bom despacho & 35288 & 39926 & 1.38 & 37205 & 93.18 \\
\hline Cachoeira da Prata & 3669 & 3778 & 0.33 & 3547 & 93.89 \\
\hline Caetanópolis & 7402 & 8571 & 1.64 & 7400 & 86.34 \\
\hline Conselheiro Lafaiete & 88843 & 102667 & 1.62 & 99345 & 96.76 \\
\hline Contagem & 448991 & 537806 & 2.03 & 533119 & 99.13 \\
\hline Cordisburgo & 8449 & 8520 & 0.09 & 5687 & 66.75 \\
\hline Corinto & 25144 & 24506 & -0.29 & 21414 & 87.38 \\
\hline Curvelo & 58992 & 67141 & 1.45 & 58829 & 87.62 \\
\hline Diamantina & 44308 & 44260 & -0.01 & 37784 & 85.37 \\
\hline Divinópolis & 151382 & 183764 & 2.18 & 177785 & 96.75 \\
\hline Felixlândia & 11934 & 12780 & 0.76 & 9445 & 73.90 \\
\hline Formiga & 61777 & 62837 & 0.19 & 55537 & 88.38 \\
\hline Inhaúma & 4767 & 5193 & 0.96 & 3464 & 66.71 \\
\hline Itabira & 85284 & 98221 & 1.58 & 89615 & 91.24 \\
\hline Itaúna & 66333 & 76783 & 1.64 & 71695 & 93.37 \\
\hline Jequitibá & 5047 & 5166 & 0.26 & 1634 & 31.63 \\
\hline João Monlevade & 59346 & 66592 & 1.29 & 66274 & 99.52 \\
\hline Maravilhas & 5534 & 6223 & 1.31 & 4102 & 65.92 \\
\hline Mariana & 38115 & 46719 & 2.29 & 38689 & 82.81 \\
\hline Matozinhos & 23636 & 30154 & 2.74 & 27657 & 91.72 \\
\hline Ouro Preto & 62495 & 66256 & 0.65 & 56284 & 84.95 \\
\hline Pará de Minas & 61066 & 72937 & 1.99 & 67924 & 93.13 \\
\hline Paraopeba & 16995 & 20378 & 2.04 & 17278 & 84.75 \\
\hline Pitangui & 20173 & 22203 & 1.07 & 18566 & 83.62 \\
\hline Pompéu & 20537 & 26026 & 2.67 & 22232 & 85.42 \\
\hline Prudente de Morais & 6769 & 8126 & 2.05 & 7819 & 95.52 \\
\hline Ribeirão das Neves & 143696 & 246589 & 6.18 & 245143 & 99.41 \\
\hline Sabará & 89736 & 115292 & 2.82 & 112630 & 97.69 \\
\hline Santa Luzia & 137686 & 184721 & 3.32 & 184026 & 99.62 \\
\hline Sete Lagoas & 143950 & 184692 & 2.81 & 180613 & 97.79 \\
\hline Três Marias & 21411 & 23539 & 1.06 & 22486 & 95.30 \\
\hline
\end{tabular}

Fonte: IBGE: Censos Demográficos 1991 e 2000 - disponíveis na internet via http://www.ibge.gov.br. 
influenciou profundamente seu destino, assim como a organização espacial de sua hinterlândia. (Mapa 1) Essa posição de contato constitui, ou pelo menos foi, durante muito tempo, o maior dos fatores que beneficiaram a cidade. De fato, a posição geográfica de contato entre duas grandes regiões no conjunto mineiro, favoreceu sobremaneira o surgimento e o desenvolvimento de certos fatores, os quais, desde a origem até a atualidade, foram, em muitas circunstâncias, os responsáveis pela construção da centralidade setelagoana. Daí a consideração de sua primeira função na rede urbana mineira, que foi a de boca-de-sertão.

Mapa 1: $\quad$ Posição de Sete Lagoas em Minas Gerais.

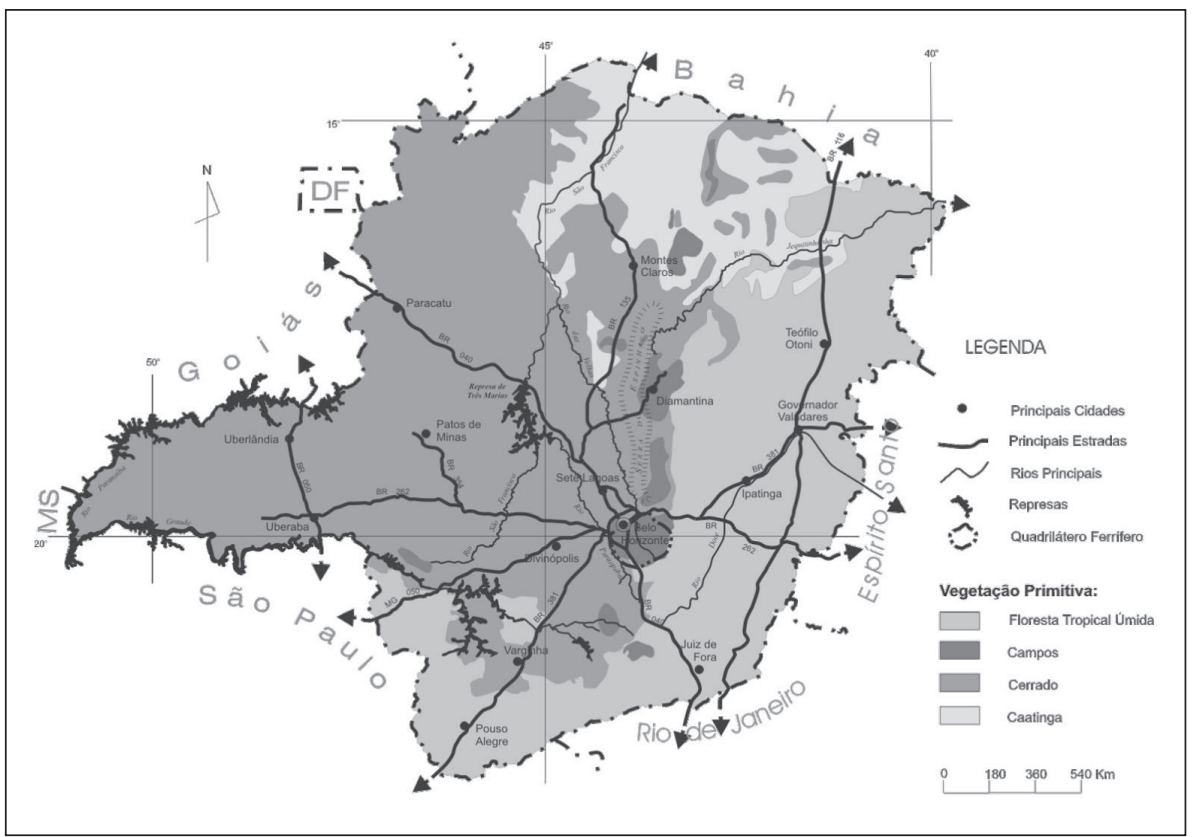

Em seus primórdios, a função de boca-de-sertão foi a responsável pela centralidade adquirida por Sete Lagoas, principalmente, porque permitiu ou favoreceu o desenvolvimento das atividades agropecuárias. Afinal, numa zona de contato geográfico entre duas regiões tão díspares e fora do centro nevrálgico da economia mineira colonial do ouro e da mineração, Sete Lagoas e região passam a dedicar-se às atividades agropecuárias. Mesmo porque, na região das Gerais a pecuária, em primeiro lugar e a agricultura, secun- 
dariamente, já eram as atividades econômicas características. Cumprindo a função de boca-de-sertão, Sete Lagoas passa a comandar uma região, situada ao norte e noroeste, cuja economia baseava-se numa pecuária extensiva muito característica de campos cerrados mais pobres e cujo traço industrial era dado unicamente por três unidades industriais da Cia. de Fiação e Tecelagem Cedro e Cachoeira, pertencente à família Mascarenhas.

Cedro, na freguesia do Tabuleiro Grande (município de Paraopeba, que, em 1953, emancipou-se deste, criando-se o município de Caetanópolis), Cachoeira, no distrito de Inimutaba (pertencente a Curvelo e atual município de mesmo nome) e a de São Vicente, no município de Baldim. Mas, o que importa reter, é como esse fato foi sendo percebido pelas elites locais e regionais em benefício próprio, embora sempre impactando fortemente a cidade. Assim, a função de boca-de-sertão se sustenta até o advento da ferrovia, fato notável em relação aos impactos relacionados ao início da afirmação regional sete-lagoana.

Com a chegada da ferrovia - Estrada de Ferro Central do Brasil - em Sete Lagoas, no ano de 1896, o relativo isolamento da cidade começa a abrandar-se e de forma cada vez mais intensa. A cidade transforma-se num importante centro distribuidor de bens e serviços não somente para sua região, como também para outras regiões mineiras, notadamente para o Norte e Vale do Jequitinhonha. Todos os setores socioeconômicos locais sofrem os impactos positivos em decorrência do advento da ferrovia. Expressivo aumento populacional, expansão do tecido urbano, grandes avanços na agropecuária e fomento importante nas atividades comerciais atacadistas e varejistas.

A cidade se transforma e, a reboque, sua hinterlândia. Exemplifica-se com Jequitibá, antigo porto fluvial no rio das Velhas, que acabou por perder sua função frente a Sete Lagoas, tendo em vista a adoção do transporte ferroviário em detrimento da navegação na circulação tanto de passageiros como de cargas, tais como a exportação de grãos e tecidos e a importação do algodão de origem da região Nordeste e do norte de Minas Gerais. Sete Lagoas, portanto, antes em nada expressiva, passa a comandar a região, suplantando outros centros urbanos, até então mais expressivos na rede urbana regional.

A presença da ferrovia em Sete Lagoas representou mais do que a simples e natural expansão dos trilhos demandando o interior de Minas Gerais. É nesse processo, que se pode identificar, pela primeira vez, a atuação da elite política sete-lagoana. De acordo com seus interesses, o traçado projetado para essa expansão foi totalmente alterado. Sabe-se que a integração nacional 
via interligação dos dois modais de transporte - ferrovia e navegação pelo rio São Francisco -, visando a incorporação do Sertão nordestino à região mais rica e desenvolvida do país, era um antigo anseio da administração central brasileira, desde os tempos da monarquia. De alguma forma, a intenção de promover tal articulação geográfica acabou por ser confirmada, quando da expansão ferroviária. Por outro lado, embora se tratasse de um projeto de âmbito nacional, os interesses locais manifestos junto à comissão responsável pela ferrovia foram considerados, uma vez que a estratégia utilizada foi muito eficiente e alcançou os resultados desejados: os trilhos passarem por território sete-lagoano. O traçado projetado inicialmente passava pelo vale do rio das Velhas, não contemplando o sítio urbano de Sete Lagoas. Ora, ferrovia significava progresso e desenvolvimento, enfim integração econômica, e a elite local não poderia perder tal oportunidade de cessar de vez com o relativo isolamento no qual estava mergulhada a cidade.

Munido de um arrojado projeto e fundamentado em argumentos geográficos e econômicos, bastante lógicos, o doutor João Antônio de Avelar, patrono de uma das mais influentes famílias locais, bastante atuante, até nos dias de hoje, parte para o Rio de Janeiro em busca do atendimento de seus interesses, os quais afinal, beneficiariam grandemente a cidade. Esse importante membro da elite local que foi várias vezes vereador, prefeito, deputado estadual e o primeiro médico que a cidade conheceu, era um político muito inteligente e perspicaz e utilizou-se de três argumentos, os quais, evidentemente foram considerados pela comissão responsável pela expansão da Estrada de Ferro Central do Brasil. Sua argumentação baseou-se na necessidade de realização de várias obras de arte para evitar as enchentes periódicas do rio, fato que encareceria a empreitada, mas, e, principalmente, o doutor Avelar sustentou-se em dois fatos econômicos irrefutáveis, ou seja, como a região de Sete Lagoas já continha uma importante e promissora indústria têxtil e já se projetava extra-regionalmente em decorrência de sua produção agropecuária, a manutenção de uma grande quantidade de carga que justificasse a circulação das mercadorias, compondo os trens, já estaria garantida. Adicione-se o fato de que a navegação pelo rio das Velhas permaneceria inalterada (previsão esta que, afinal não se concretizou, tendo em vista o abandono total da navegação tanto para o transporte de passageiros, como para o de cargas). A região, mas, notadamente, a cidade de Sete Lagoas, por isso, viu-se muito beneficiada, pois, finalmente, a mudança do traçado vingou e passou do vale para o espigão no qual se assenta a cidade. Essa articulação das funções políticas e econômicas representadas na figura 
do doutor Avelar foi crucial no sentido de significar a primeira movimentação em direção à construção da centralidade de Sete Lagoas na rede urbana mineira (Nogueira, 2003, BоTTOMORE, 1974).

Em meados da década de 1930, a cidade já se configurava como importante centro comercial atacadista, abastecendo boa parte do norte do estado de Minas Gerais, atingindo inclusive o vale do Jequitinhonha. O cenário era de intensa expansão econômica e uma poderosa classe ruralista, a qual vai definir, quase durante todo o século XX, os destinos da cidade, já havia se formado, além de também uma importante classe de comerciantes que já se destacava. Em 1936 é criada a Associação Comercial da cidade, a qual representou tanto o condicionante como o efeito do expressivo crescimento econômico local. Evidentemente, importa destacar, que a criação de uma associação dessa natureza significou uma das estratégias mais eficazes em direção ao reforço da centralidade sete-lagoana, uma vez que seus membros fundadores pertenciam (como pertencem até a atualidade) tanto à classe política como à econômica. Na verdade, essas duas classes se confundem na história da construção da centralidade sete-lagoana. Cabe ressaltar, porém, que o enorme desenvolvimento da pecuária leiteira e a escolha da cidade como local de instalação da primeira fábrica de leite em pó da Itambé (e, também, a primeira fábrica da empresa fora de sua sede - Belo Horizonte), ainda em fins dos anos de 1940, reforçam o fato de que, não obstante o enriquecimento e aumento de poder da classe dos comerciantes, será a classe dos ruralistas que mais vai se destacar em todo o cenário históricogeográfico do lugar. Exemplificando, basta mencionar o fato de que, durante até a década de 1950, entre os principais diretores e também os presidentes da ACI, os ruralistas foram os predominantes (ACI - Sete Lagoas, 1996, NOGUEIRA, 2003).

Como já mencionado, a posição geográfica de Sete Lagoas sempre foi um fato perceptível para as elites locais, no sentido de como elas se aproveitaram desse fato em prol de si mesmas e, assim beneficiaram a cidade, reforçando gradativamente o comando da vida de relações da região sete-lagoana e, porque não dizer, a sua centralidade na rede urbana mineira.

A afirmação da agropecuária, por meio da transformação da cidade em centro de pesquisa nesse setor e em líder da maior bacia leiteira do estado de Minas Gerais (atualmente essa posição foi perdida pela bacia comandada por Bom Despacho), são fatos exemplares de tal assertiva. A pesquisa agropecuária já está em Sete Lagoas, desde o princípio do século $\mathrm{XX}$, época na qual foi criado um pequeno centro de experiência ("campos 
experimentais”), em terras de cerrado, onde se poderia verificar a utilização e o comportamento de determinadas culturas agrícolas (AvELLAR e Silva, 2000). Em 1956 o Campo de Cereais e Leguminosas, um órgão estadual, transformou-se em um instituto de pesquisa federal, o afamado Instituto Agronômico do Oeste (IAO) e para que sua localização recaísse em Sete Lagoas, concorreu a atividade do então deputado estadual Dr. Márcio Paulino, também um dos mais ilustres representantes da elite local, além de ser patrono de uma das famílias que ainda, na atualidade, continuam no comando de alguns setores da política e da economia da cidade. As ingerências promovidas pelo deputado foram cruciais para que Sete Lagoas recebesse a sede de tão importante instituto de pesquisa agropecuária. Para o deputado, porque localizar o centro em Alfenas (tal qual parecer do relator do processo apontava, à época, na Assembléia Legislativa), se os custos seriam em muito minimizados, na medida em que em Sete Lagoas já existia uma infra-estrutura implantada?

Em 1962 o IAO foi transformado em Instituto de Pesquisa e Experimentação do Centro-Oeste (IPEACO), semente já bastante desenvolvida da qual foi criado o atual Centro Nacional de Pesquisa de Milho e Sorgo (CNPMS), pertencente à Embrapa. Sete Lagoas, definitivamente, torna-se uma referência nacional (e internacional) no que diz respeito à pesquisa agropecuária para o Cerrado.

A trajetória da criação ou da "permanência" de um centro de pesquisa dessa natureza na cidade seguiu caminhos bastante semelhantes aos acima descritos, ou seja, novamente, concorreram para tal concretização as intervenções do então deputado federal Renato Azeredo, neto pelo lado materno do Doutor João Avelar. Realmente, trata-se de uma estirpe de homens que forjados na política local, alcançaram os mais altos cargos na política nacional, fato crucial no sentido de acabar por beneficiar a cidade de Sete Lagoas.

O fato é que, a cidade, antes foco central de pesquisas relativas aos cultivos de leguminosas, cereais e algodão, tornou-se um lugar estratégico para a continuidade da pesquisa agropecuária no país, justamente por se localizar na entrada do Sertão, ou seja, por ser a porta de entrada do cerrado brasileiro. Essa centralidade foi, portanto mais uma vez reconfirmada, quando da criação da Embrapa, em 1973, ou seja, mais uma vez concorreram para levar para Sete Lagoas um dos centros nacionais de pesquisa dessa empresa, os fatores conjugados de sua posição geográfica estratégica e sua longa tradição na área da pesquisa agropecuária. 
Embora possua sede no vizinho município de Prudente de Morais, o Centro Tecnológico do Centro-Oeste (CTCO) da Empresa Mineira de Pesquisa Agropecuária (EPAMIG), é mais conhecido pela alcunha de "Epamig de Sete Lagoas". Esse também pode ser apontado como um indicativo da centralidade sete-lagoana, mesmo porque, com objetivos e estrutura muito semelhantes aos da Embrapa, o CTCO mantém íntimas relações de complementaridade com o órgão federal.

A pecuária leiteira constituiu um verdadeiro fator de centralização política e econômica para Sete Lagoas. A classe ocupacional dos ruralistas sempre dominou os diversos setores da cidade. Grandes pecuaristas foram também médicos, vereadores, presidentes da Associação Comercial e Industrial (ACI), prefeitos, além de deputados nas duas casas legislativas, a federal e a estadual, ao longo de praticamente todo o século XX. A conjunção do poder econômico com o poder político fez destes homens, agentes dos mais importantes para a construção e o constante reforço da centralidade sete-lagoana. Desse modo as estratégias por eles envidadas tiveram um enorme sucesso, tanto para o reforço e a manutenção de seu status quo, como também beneficiando a cidade.

A criação de um banco agrícola, de uma associação rural e de uma cooperativa rural são exemplares do poder alcançado pela classe ruralista em Sete Lagoas. Embora hoje em fase de liquidação extrajudicial, o Banco Agrícola de Sete Lagoas, mais tarde tornado AGRIMISA, foi fundado em 1925, época na qual casas bancárias e bancos, propriamente ditos, eram uma quase uma exclusividade da região sul de Minas Gerais, como decorrência do poderio da economia cafeeira (Costa, 1978). Realmente, o surgimento de um empreendimento da natureza de um banco, naquela região, constituiu uma localização muito excêntrica. De um pequeno banco nascido no Sertão, o Agrimisa, em meados da década de 1980, já tinha alcançado uma dimensão de banco nacional, na medida em que, sua rede de agências atingiu as principais capitais brasileiras, além de importantes cidades médias do interior do estado e do país (Nogueira, 2003).

A Associação Rural Centro de Minas e a Cooperativa Regional dos Produtores Rurais de Sete Lagoas (Coopersete), ambas criadas ainda durante os anos de 1930 e 1940, respectivamente, representam expressões contundentes do grande peso econômico da atividade pecuarista e do poder alcançado por seus representantes, os proprietários fundiários, uma parte muito importante da elite local. No caso da primeira, concorreu para sua criação a conjuntura altamente favorável em nível nacional: trata-se da fase da "fe- 
bre do zebu", quando os incentivos e os créditos destinados à introdução dessa raça no Brasil e a especulação financeira, daí advinda, enriqueceu muita gente, entre os quais boa parte dos pecuaristas sete-lagoanos. Na atualidade, o Sindicato Rural de Sete Lagoas permanece tão forte hoje, como, quando foi criado. No que tange à Coopersete, sua força também é muito grande, uma vez que reúne grandes pecuaristas não somente sete-lagoanos, como também de outros municípios da hinterlândia e até mesmo de outros municípios fora dessa (municípios metropolitanos tais como Ribeirão das Neves e Esmeraldas) (Nogueira, 2003). Para a Itambé (Cooperativa Central dos Produtores Rurais - CCPR) a bacia leiteira comandada por Sete Lagoas sempre foi das mais produtivas e importantes de sua rede e sua associada - a Coopersete (Cooperativa regional dos Produtores Rurais de Sete Lagoas), se encontra no mesmo nível de importância.

Todos os processos descritos até agora dizem respeito à construção da centralidade urbana de Sete Lagoas e consequentemente à sua inserção na economia de Minas Gerais. Esse processo inicial deu-se ao longo de toda a primeira metade do século XX e, pode-se afirmar, que termina com a instalação das primeiras siderúrgicas não-integradas de ferro gusa na cidade no ano 1959. Novamente, a posição geográfica privilegiada de Sete Lagoas vai ser um fator definitivo para que o centro guseiro estadual se transferisse das cidades de Divinópolis e Itaúna para a cidade. Localizada às margens da antiga MG-1 (atual MG 424) e mais tarde aproveitada para a implantação da rodovia BR 040 (Rio de Janeiro - Brasília) e possuindo grandes jazimentos de calcário, Sete Lagoas mostrou-se muito mais atrativa para a nascente indústria do gusa num país que se modernizava. Malha viária, matéria-prima abundante e porta de entrada do Sertão, fornecedor do carvão vegetal combinaram-se com perfeição para que hoje, Sete Lagoas, seja considerada o maior pólo guseiro não-integrado do país (Nogueira, 2003).

Permeando todo o longo processo de construção da centralidade de Sete Lagoas, processo esse iniciado em fins do século XIX, além das estratégias e ações acima analisadas, outras estratégias foram tomadas no sentido de prover a cidade de certos atributos, os quais, certamente, significaram mais um elemento fundamental nessa construção. Trata-se das estratégias seguidas com relação aos setores da educação e saúde, por meio da criação de um hospital, no princípio de século XX o qual, hoje, é referência regional e de duas importantes escolas, uma de ensino médio e a outra de ensino superior na cidade (ambas nos anos de 1960). Esses equipamentos permane- 
cem possuindo um papel muito expressivo nos dias de hoje na manutenção da centralidade de Sete Lagoas.

A mudança na mentalidade da elite sete-lagoana pode ser apontada como o aspecto mais importante do processo atual de construção-manutenção de sua centralidade. Para perpetuar sua condição autônoma na atualidade, novas atividades econômicas foram agregadas à base econômica local, tais como o setor de autopeças, de capital predominantemente italiano, embora haja uma empresa de capital local e a montagem de veículos utilitários leves, a IVECO, do grupo FIAT. Aos olhos desavisados essas novas atividades constituem o resultado da performance da cidade, como se o capital, pudesse por ele mesmo, decidir sobre onde atuar para alcançar seus objetivos. Ora, o processo descrito e analisado nesse trabalho tentou mostrar que a visão que considera uma ação como que estruturada sobre uma pretensa "mão invisível do mercado", com agentes imateriais e impessoais no controle do processo, não deve ser mais considerada. Afinal, por detrás de toda e qualquer estratégia e ação empreendida está o homem, com suas ambições e vontades, o agente social concreto da construção do espaço geográfico. Essa desmistificação é necessária e trará como benefício primeiro à elevação da ação humana e sua historicidade à sua real condição, da mais importante categoria do acontecer geográfico, histórico e social.

No que tange às interações com Belo Horizonte é importante destacar que a proximidade da metrópole foi benéfica para Sete Lagoas, na medida em que a competente elite local sete-lagoana criou uma série de atividades em função da capital, estabelecendo bases sólidas para o seu próprio crescimento, durante um período, até cerca de 1960, antes que a capital mineira pudesse polarizar a região próxima e concentrar tudo em si mesma. Além do mais, saliente-se que, em boa medida, o papel político que a capital exerceu até os anos de 1960 foi controlado por uma elite regional, em cujos quadros figurou a elite local sete-lagoana (NogUeIRA, 2003).

O processo de construção da singularidade da cidade de Sete Lagoas mostra que esse lugar geográfico esteve e está sujeito às contingências históricas, às condições econômicas e à política, processos que são gerados tanto local, como também, universalmente. No decorrer desse processo maior que, saliente-se, é infindável, a singularidade de Sete Lagoas tornou-se inteligível e pode ser assim sumariada: trata-se de uma cidade média que, localizada muito próxima à metrópole belo-horizontina, conseguiu forjar uma forte autonomia relativa e que, por causa disso, possui uma inserção bastante privilegiada, guardadas as devidas proporções, na rede urbana mineira. 
Sete Lagoas é uma cidade média que, como muitas outras hoje espalhadas pelo interior do país, possui uma grande capacidade de concentrar as atividades do trabalho e da técnica, pois como controlam a vida de relações de suas respectivas regiões, delas dependem e por elas passam todos os fluxos gerados pelas atividades regionais, notadamente, aquelas referentes ao campo (SAntos e Silveira, 2001).

Entretanto, restam alguns questionamentos. Como manter essa centralidade frente à expansão do processo de metropolização belo-horizontino? Qual deve ser o papel exercido pela elite sete-lagoana diante de tal desafio, tendo em vista não somente a necessidade de novas mentalidades e novas estratégias, como também, o ambiente da globalização atual, no qual, um dos aspectos fundantes é a concorrência entre os lugares geográficos, visando a atração dos investimentos? Enfim, como prosseguir no processo da construção-manutenção da centralidade de Sete Lagoas na rede urbana mineira, sem perder de vista o papel crucial exercido pelas elites sociais locais?

\section{Referências}

ASSOCIAÇÃO COMERCIAL E INDUSTRIAL DE SETE LAGOAS. Sessenta anos de lutas pelo desenvolvimento da cidade e da região: 1936-1996. Sete Lagoas: ACI-SL, 1996 (publicação comemorativa dos 60 anos de fundação da ACI-Sete Lagoas).

AVELLAR, Gisela de, SILVA, Arnaldo Ferreira da. Novas trilhas no Sertão: história da pesquisa agropecuária em Sete Lagoas: das origens à Embrapa. Sete Lagoas: EMBRAPA Milho e Sorgo, 2000 .

BERNARDES, Lysia Maria Cavalcanti. O Rio de Janeiro e sua região. Rio de Janeiro: IBGE. 1964.

BOTTOMORE, Tom. As elites e a sociedade. 2 ed. Rio de Janeiro: Zahar. 1974.

COSTA, Fernando Nogueira da. Bancos em Minas Gerais (1889-1964). Campinas, SP: IFCH/ UNICAMP, 1978. Dissertação. (Mestrado em Economia).

FUNDAÇÃO CENTRO TECNOLÓGICO DE MINAS GERAIS (CETEC), INSTITUTO DE GEOCIÊNCIAS APLICADAS (IGA). Estado de Minas Gerais: regiões administrativas. Belo Horizonte: Fundação João Pinheiro, CETEC/IGA, 1997.

FUNDAÇÃO IBGE. Divisão do Brasil em regiões funcionais urbanas. Rio de Janeiro: Fundação Instituto Brasileiro de Geografia e Estatística, DEGEO, 1972.

FUNDAÇÃO IBGE. Divisão regional do Brasil em mesorregiões e microrregiões geográficas. Rio de Janeiro: Fundação Instituto Brasileiro de Geografia e Estatística, 1992.

FUNDAÇÃO IBGE. Regiões de influência das cidades. (Coordenação: Roberto Lobato Corrêa). Rio de Janeiro: Fundação Instituto Brasileiro de Geografia e Estatística, Diretoria de Geociências, 1987. 
NOGUEIRA, Marly. Sete Lagoas: a dinâmica funcional de um lugar na rede urbana de Minas Gerais. Rio de Janeiro: UFRJ/IGEO, 2003. (Doutorado em Geografia).

SANTOS, Milton, SILVEIRA, Maria Laura. O Brasil: território e sociedade no início do século XXI. Rio de Janeiro: Record, 2001.

MARLY NOGUEIRA - Professora Doutora do Departamento de Geografia, Instituto de Geociências - UFMG.

Recebido para publicação em maio 2005

Aceito para publicação em setembro 2005 